\title{
An in- vitro study to compare and evaluate the hardness of various commercially available provisional restorative materials
}

\author{
K. Sayed Akber Pasha ${ }^{1, *}$, Sandeep Bhatia ${ }^{2}$, Gaurav Pandav ${ }^{3}$ \\ ${ }^{1}$ Prosthodontist, ${ }^{2,3}$ Senior Lecturer, ${ }^{\mathbf{1}}$ Dept. of Prosthodontics, ${ }^{2}$ Dept. of Orthodontics, ${ }^{3}$ Department of Periodontics, ${ }^{\mathbf{1}}$ Salmar, \\ Karkala, Karnataka, ${ }^{2}$ Daswani Dental College, Kota, Rajasthan, ${ }^{3}$ Guru Nanak Dev Dental College and Research Institute, Sunam, \\ Punjab, India \\ *Corresponding Author: \\ Email: drpashaksa@yahoo.com
}

\begin{abstract}
Introduction: Till a prosthodontist provides the patient with a definitive restoration, he/she should be given a provisional restorative materials. These materials should be biologically, mechanically and esthetically compatible and useful to the patient. Some physical and mechanical properties of these provisional restorations are of extreme importance, like flexural strength, hardness, wear resistance. The importance is to withstand the environment of the oral cavity. So, in this study, we have done this in-vitro study to compare and evaluate the hardness of four of the provisional restorative materials available commercially.

Materials and Methods: 10 samples each of four commercially available provisional restoration materials namely Integrity, Protemp 4, Systemp B and C and Structure 2SC were made and VHN was checked to see the hardness and thus wear resistance of these materials.

Results and Conclusion: In the present study, significant difference was not found in the hardness values for Voco and Systemp $\mathrm{C}$ and $\mathrm{B}$ whereas Protemp 4 shows greater hardness values than the rest three.
\end{abstract}

Keywords: Hardness, Wear resistance, Provisional restoration.

\section{Introduction}

Fixed partial dentures and definitive crown treatments after root canal treatment are preceded by some steps requiring provisional crowns. So, we can also say that fixed prosthodontic treatments are highly based on provisional crowns and fixed partial dentures which compose to be the vital components of such treatments. ${ }^{1}$ These components ought to protect the pulp from any chemical, thermal or physical injury till a definitive treatment is given. Also, they should maintain a proper occlusal function as well as stability and good esthetics. Until definitive restorations can be placed, the provisional restorative materials should fulfill biologic, mechanical and esthetic requirements of the patient. ${ }^{2}$ Some physical and mechanical properties of these provisional restorations are of extreme importance, like flexural strength, hardness, wear resistance. These materials are temporary but they should last enough time in the oral cavity to fulfill their requirements. The importance is to withstand the environment of the oral cavity. ${ }^{3}$ Various materials used as provisional restorations include methyl methacrylates, ethyl methacrylates, bis-acryl resin composites etc. such restorations also act as an effective diagnostic tool to check any alteration in occlusion or an evoked pulpal response. ${ }^{4}$

Many materials are combined to achieve proper esthetics of the restorative substance including many pigments, monomers, filler, initiator etc. ${ }^{5}$ The monomer is the most important component which is converted to polymer by a chemical reaction. This polymer withstands the occlusal forces and the oral environment till a definitive restoration is provided. ${ }^{3}$
So, the provisional restoration can be divided into either a fixed or removable prosthesis which are made to provide proper esthetics and functional stability for a sometime and then it is to be replaced with a final definitive prosthesis. ${ }^{6}$ All the clinicians should be familiar with all the interim materials along with their mechanical properties that are available commercially in order to make the right choice of material according to the case conditions. ${ }^{5}$

So, in this study, we have aimed to compare and evaluate the hardness of four of the provisional restorative materials available commercially.

\section{Materials and Methods \\ Materials Include:}

1. Protemp 4: Bis acryl resin based containing bifunctional methacrylates

2. Integrity: Bis acryl resin based containing multifunctional methacrylates

3. Systemp C and B: Bis acryl resin based containing methacrylates

4. Structure 2SC: Bis acryl resin based containing methacrylates

Mold Description: According to ADA specifications no.13, the master die was machined $(64 \mathrm{~mm} \times 3.5 \mathrm{~mm}$ $\times 12.3 \mathrm{~mm} \times 65 \mathrm{~mm} \times 13.5 \mathrm{~mm}$ ) to determine hardness. Then, the mold was prepared. $100 \mathrm{~g}$ powder: $30 \mathrm{ml}$ water ratio was used to fill the lower portion of the brass flask in which stainless steel dies were then placed. The second half of the flask was filled with dental stone after applying cold mold seal on the previous set mixture and flasking was done. The flask was then placed on the bench press and allowed to set. 
After the set was achieved, the flasks were opened and the dies were removed from the lower flasks.

Specimen Fabrication: Auto mixing gun was used to dispense provisional restorative material into the mold space. This mold was properly secured in place by a bench press and allowed to cure according to the manufacturer's instructions. The flasks were then opened after the specimens had polymerized properly. The specimens were then removed using a BP blade no 12 and grossly trimmed and polished. 40 total specimens were prepared in the similar way, 10 specimens of each test material.

Specimen Testing: Vicker's hardness number was determined after $24 \mathrm{hr}$ as a baseline value with the micro hardness tester. A force of $100 \mathrm{~g}$ was used on each specimen for 15 s. A square pyramid shaped indentation was obtained on each specimen and this image was then transferred to the computer monitor.

Formulae Used: The following formula was used after measuring the lengths of the diagnols and to measure the VHN for 40 samples:

$\mathrm{HV}=2 \mathrm{Fsin} 136$ degree $/ 2$ divided by $\mathrm{d}^{2}$

Anova test was used for statistical analysis and post hoc tests were done to check the significance.

\section{Results}

The descriptive analysis of mean and SD for hardness of the four test materials has been shown in Table 1 .

Table 1: Mean and standard deviation of hardness (Vickers hardness number) values between four different provisional restorative materials $(n=10)$

\begin{tabular}{|l|c|c|c|}
\hline Protemp 4 & Integrity & Systemp B and C & Structure 2SC \\
\hline 66.4 & 61.2 & 56.3 & 55.1 \\
\hline 64.2 & 60.9 & 55.8 & 54.2 \\
\hline 63.6 & 62.9 & 56.7 & 53.5 \\
\hline 67.1 & 60.7 & 52.7 & 50.1 \\
\hline 65.8 & 60.9 & 54.3 & 50.3 \\
\hline 65.4 & 59.8 & 53.2 & 52.3 \\
\hline 66.3 & 60.8 & 54.1 & 53.2 \\
\hline 65.8 & 61.1 & 53.2 & 52.9 \\
\hline 60.5 & 58.7 & 50.8 & 53.2 \\
\hline 64.3 & 60.9 & 52.7 & 53.8 \\
\hline
\end{tabular}

Table 2 depicts the one-way ANOVA to check significance.

Table 2: Statistical comparison (one-way analysis variance of hardness) (Vickers hardness number) values between different provisional restorative materials

\begin{tabular}{|l|c|c|c|c|c|c|c|}
\hline $\begin{array}{c}\text { Provisional } \\
\text { restorative } \\
\text { material }\end{array}$ & $\begin{array}{c}\text { Source of } \\
\text { variance }\end{array}$ & $\begin{array}{c}\text { Degree of } \\
\text { freedom }\end{array}$ & $\begin{array}{c}\text { Sum of } \\
\text { squares }\end{array}$ & $\begin{array}{c}\text { Mean of } \\
\text { squares }\end{array}$ & F & P & Remarks \\
\hline Protemp 4 & Between groups & 36 & 49.234 & 1.368 & & & \\
\hline Integrity & $\begin{array}{c}\text { Within the } \\
\text { groups }\end{array}$ & 3 & 558.644 & 186.215 & 136.161 & 0.001 & $\mathrm{~S}$ \\
\hline Structure 2SC & & 39 & 607.870 & & & & \\
\hline Systemp C and B & & & & & & & \\
\hline
\end{tabular}

In four types provisional restorative materials the hardness differ significantly at 5\% level of significance (P

Table 3 is depiction of post hoc tests. In the present study, no significant difference was found in the hardness values for Voco and Systemp C and B whereas Protemp4 shows greater hardness values than the rest three.

Table 3: Post hoc analysis of hardness (Vickers hardness number) values between different provisional restorative materials

\begin{tabular}{|l|c|c|c|c|}
\hline \multicolumn{1}{|c|}{ Material (I) } & Material (J) & Mean difference (I-J) & SE & P \\
\hline Structure 2SC & Integrity & $-3.09^{*}$ & 0.52 & 0.0001 \\
& Protemp 4 & $-8.76^{*}$ & 0.51 & 0.000 \\
& System C and B & 0.68 & 0.51 & 1.000 \\
\hline Integrity & Protemp 4 & $-5.69^{*}$ & 0.51 & 0.000 \\
& System C and B & $3.78^{*}$ & 0.51 & 0.000 \\
\hline Protemp 4 & System C and B & $9.37^{*}$ & 0.51 & 0.000 \\
\hline
\end{tabular}

* Statistically significant, $\mathrm{SE}=$ Standard error 


\section{Discussion}

This study is about the provisional restorative materials which are an intricate part of the fixed prosthodontic treatments. Many prefabricated as well as custom made materials are available for provisional restorations like clear celluloid shells, metal crowns, polycarbonate crowns, polymethacrylate, bisacryl composite etc. $^{7}$

Not only the materials have variety but also various techniques are used to fabricate the provisional restorations using auto polymerizing resins with the advent of new composite materials like light or dual cures etc. ${ }^{8}$ Composites are better because they do not cause chemical irritation like acrylic.

One major factor of determination to rate a provisional restorative material is density. Density is measured by using surface hardness as an indicator as a dense material is better resistant to surface deterioration and wear. ${ }^{9}$ Amongst the materials with good wear resistance, the perforation risk is highly reduced and the structural integrity is maintained.

Another indispensible factor is hardness of the material. Many types of hardness tests are available including Vickers, Knoops, Shore, Rockwell etc. In the present study, VHN was used to determine the hardness values for four test materials. This test is basically based on the resistance that the material shows to the penetration of a specific tip when a given load is applied for a specific period of time. In the present study, the hardness of four commercially available materials has been compared using VHN and this helped to give a descriptive result of the hardness which is of value ${ }^{10}$ Many similar studies in the past have been done on various materials and has significantly helped in determining a good provisional restorative material from the buyer point of view.

The present study was done to evaluate in vitro hardness of integrity, structure 2SC, Systemp C and B and Protemp 4. The provisional restorative material represent different chemical contents i.e. integrity from dentsply group represent methacrylates with barium glass and fumed silica, structure 2SC from Voco group represent methacrylates with terpenes, amines and benzoyl peroxide, butylated hydroxy toluene, Systemp $\mathrm{C}$ and $\mathrm{B}$ from Ivoclar Vivadent group represent polyfunctional methacrylates and inorganic fillers, plasticizers and stabilizers, Protemp 4 from 3 M ESPE group contains dimethacrylate polymer and bis gma resins with fillers and stabilizers represents however the contents and except a few descriptive words regarding strength have not been disclosed by the manufacturer. These materials have different compositions but the strength and proper descriptive words are not disclosed by the manufacturer. So, this study has proved useful in selection of particular material for a particular case. Protemp 4 from 3M ESPE has showed greatest hardness values and is thus significantly hard as compared to the three other materials evaluated in this study. Clinicians should consider all the attributes of the provisional materials like hardness, wear resistance, wear in response to the insult by the oral fluids, temperature etc. It has been proved by many previous studies on temporization materials that composite based materials show better hardness values. This can be attributed to the higher degree of conversion and the presence of increased number of cross-linking agents which result in the hardness of the material.

So, the present study has evaluated the hardness values of four composite based materials. Amongst this Protemp 4 has been found to be the hardest followed by Integrity. Structure B \&C and Structure 2SC have significantly lesser hardness than both Protemp 4 and Integrity but the values are insignificant when they are compared with each other.

\section{References}

1. Patras M, Naka O, Doukoudakis S, Pissiotis A. Management of provisional restorations' deficiencies: A literature review. J Esthet Restor Dent 2012;24:26-38.

2. Ireland MF, Dixon DL, Breeding LC, Ramp MH. In vitro mechanical property comparison of four resins used for fabrication of provisional fixed restorations. J Prosthet Dent 1998;80:158-62.

3. Nejatidanesh F, Momeni G, Savabi O. Flexural strength of interim resin materials for fixed prosthodontics. J Prosthodont 2009;18:507-11.

4. Hernandez EP, Oshida Y, Platt JA, Andres CJ, Barco MT, Brown DT. Mechanical properties of four methylmethacrylate-based resins for provisional fixed restorations. Biomed Mater Eng 2004;14:107-22.

5. Luthardt RG, Stössel M, Hinz M, Vollandt R. Clinical performance and periodontal outcome of temporary crowns and fixed partial dentures: A randomized clinical trial. J Prosthet Dent 2000;83:32-9.

6. Lappalainen R, Yli-Urpo A, Seppä L. Wear of dental restorative and prosthetic materials in vitro. Dent Mater 1989;5:35-7.

7. Rosentiel SF, Land MF, Fujimoto J. Contemporary Fixed Prosthodontics. New Delhi, India: Elsevier Inc.; 2007. p. 466-504.

8. Haselton DR, Diaz-Arnold AM, Vargas MA. Flexural strength of provisional crown and fixed partial denture resins. J Prosthet Dent 2002;87:225-8.

9. Baldissara P, Comin G, Martone F, Scotti R. Comparative study of the marginal microleakage of six cements in fixed provisional crowns. J Prosthet Dent 1998;80:417-22.

10. Craig's Restorative Dental Materials. 12th ed. Philadelphia. United States: C V Mosby; 2006. p.161-98. 